\title{
Medication errors in critical care: risk factors, prevention and disclosure
}

\author{
Eric Camiré MD, Eric Moyen MD, Henry Thomas Stelfox MD PhD
}

An abridged version of this article appeared in the Apr. 28, 2009, issue of CMAJ and is available online at www.cmaj.ca/cgi/content/full/180/9/936/DC2

\section{The case}

Mr. S, a 63-year-old man with a recent history of peptic ulcer disease who is taking proton pump inhibitor therapy (his only medication) as an outpatient, is admitted to the intensive care unit (ICU) with respiratory distress. Community-acquired pneumonia is diagnosed, although pulmonary embolism was considered in the differential diagnosis. Treatment with both antibiotics and intravenous heparin is initiated. Over the next 24 hours, the patient's clinical condition improves, and his care is transferred to the medical teaching unit. Before discharge from the ICU, a computed tomography chest scan with contrast confirms the absence of a pulmonary embolism. On day 4 after admission, hematemesis, hypotension and respiratory distress develop. The patient is intubated, readmitted to the ICU and given 6 units of blood. Endoscopy shows an actively bleeding peptic ulcer. The patient's intravenous heparin therapy is stopped. Protamine is administered because his partial thromboplastin time is greater than 150 seconds, and a proton pump inhibitor is prescribed.

Why did this medication error occur? What could have been done to prevent this error? How should the medical team proceed?

\section{Medication errors in critical care}

Critically ill patients admitted to an ICU experience, on average, 1.7 medical errors each day, and many patients suffer a potentially life-threatening error during their stay. ${ }^{1,2}$ Medication errors are the most common type of error and account for $78 \%$ of serious medical errors in the ICU. ${ }^{3}$ Providing 1 critically ill patient with a single dose of a single medication requires correctly executing 80-200 steps. ${ }^{4}$ The medication process involves 5 broad stages: prescription, transcription, preparation, dispensation and administration. ${ }^{5}$ Medication errors, defined as any error in the medication process regardless of whether a patient experiences an adverse consequence, can occur at any step. ${ }^{6}$ It is important to have an understanding of the risk factors for medication errors and the evidence base for preventing medication errors and disclosure, should an error occur.

Although the medication process is similar for all patients in hospital, we have restricted our review to studies focused on critically ill adult patients because the environment, patient characteristics and medications used in the ICU are substantially different from those in other hospital units. ${ }^{7}$ The ICU brings together high-risk patients who require urgent, complex interventions from multiple health care professionals in a complex environ-

\section{Key points}

- Medication reconciliation may improve patient safety in the intensive care unit, and an updated list of medications should be maintained, including long-standing medications, the reasons for starting new medications and their planned stop dates and the reasons for discontinuing or holding old medications.

- Engaging pharmacists in inpatient rounds in the intensive care unit may decrease the risk of adverse drug events.

ment where patients are exposed to twice as many medications as those in general medical wards. ${ }^{78}$ In addition, critically ill patients differ from most other hospital patients because they have limited ability to participate in their medical care and lack the physiologic reserve to tolerate additional injury.

\section{Methods}

Our search strategy (Appendix 1, available at www.cmaj.ca/ cgi/content/full/180/9/936/DC1) resulted in the identification of 1168 citations: 870 from MEDLINE, 262 from EMBASE and 36 from Evidence-Based Medicine Reviews. Of these, 57 full-text articles met our initial inclusion criteria and were retrieved for assessment (Appendix 2, available at www.cmaj. ca/cgi/content/full/180/9/936/DC1). An additional 5 articles were selected from the reference lists of the retrieved articles. After assessment, 17 articles ${ }^{3,7,9-23}$ remained for review. These articles were published between 1950 and 2008. We extracted key elements from the selected studies, including study design, study population, recruitment and sampling, blinding, attrition rates and statistical methods (Appendix 3, available at www.cmaj.ca/cgi/content/full/180/9/936/DC1).

\section{What is the incidence of medication errors in the intensive care unit and what are the risk factors?}

From 49 of the articles retrieved in our search, we identified and categorized potential risk factors for medication errors in the ICU (Box 1). Only 6 of these studies satisfied our inclusion criteria. The first used a survey of nurses and physicians

From the Departments of Critical Care Medicine (Camiré, Moyen, Stelfox), Community Health Sciences (Stelfox) and Medicine (Stelfox), University of Calgary, Calgary, Alta. 
to examine the point prevalence of sentinel events and their risk factors in 205 ICUs in 29 countries. $^{9}$ Medication errors were the second most frequent sentinel event, with a point prevalence of 10.5 medication errors per 100 patient-days. The frequency of medication errors was similar during the prescription $(54 \%)$ and administration $(46 \%)$ phases of the medication process. Multiple variable logistic regression analysis revealed that the patient-to-nurse ratio in the ICU (range 1.3:1 to $2: 1$ ), exposure time to medications, organ failure and the high level of care provided to each patient were independent risk factors for sentinel events including medication errors.

The second was a prospective cohort study of 4031 medical and surgical patients admitted to 5 ICUs and 6 general care units over 6 months. ${ }^{7}$ Adverse drug events and medication errors were identified by direct reporting, investigator visits to each care unit and chart review. In this study, 2 physician reviewers independently evaluated all potential adverse drug events, and structured interviews were performed to determine the circumstances of the adverse event. The number of preventable and potential adverse drug events per 1000 patient-days was higher in ICUs than in general care units $(19 \mathrm{v}$. $10, p<0.01)$, but the number was similar after adjustment for the number of medications prescribed (1.27 v. 1.07 per 1000 patient-days per prescribed medication). The rate of preventable and potential adverse drug events was higher in medical ICUs (25 per 1000 patient-days) than in surgical ICUs (14 per 1000 patient-days) $(p<0.05)$ with similar numbers of medications prescribed in both types of ICU. A similar finding was reported in the third article, a multicentre prospective trial of safety incidents. ${ }^{10}$ This study reported that medication errors were more frequent in medical ICUs than in surgical ICUs (13\% v. $6 \% ; p \leq 0.001) .{ }^{10}$ Cullen and colleagues $^{7}$ also found that most medication errors occurred during either the administration $(44 \%)$ or ordering $(38 \%)$ phase of the medication process. Interviews suggested that most errors occurred during what caregivers perceived as normal working conditions.

The study by Calabrese and colleagues ${ }^{11}$ reported medication errors in a cohort of 851 patients admitted to 5 ICUs over 3 months. Pharmacists prospectively monitored each patient twice daily using direct observation and review of the administered medications. Medication errors were identified during 187 of the 5744 ob- servations $(3.3 \%)$. The most frequently reported errors were wrong infusion rate $(40.1 \%)$, dose omission $(14.4 \%)$, improper dose $(11.7 \%)$ and wrong time $(13.9 \%)$. The authors identified vasoactive medications $(32.6 \%)$ and sedatives or analgesics $(25.7 \%)$ as the medication classes most commonly associated with error.

In the fifth study, ${ }^{12}$ pharmacists directly observed the preparation and administration process for 2009 prescriptions filled by nurses. They identified errors in $6.6 \%$ of the observations and characterized the most frequent errors as errors in

\section{Box 1: Potential risk factors for medication errors in the intensive care unit (ICU)}

\section{Patients}

- Severity of illness* ${ }^{9}$

- Any organ failure (OR 1.13, 95\% Cl 1.00-1.29)

- High intensity of care (OR 1.62, 95\% Cl 1.18-2.22)

- Lack of a usual medication list ${ }^{21}$ (for $94 \%$ of ICU patients, medication orders are changed after home medications are verified and medical records reviewed)

- Need for sedation and mechanical ventilation ${ }^{5,24}$

- Extremes of age $\mathrm{e}^{24-28}$

Providers

- Inexperience ${ }^{1,29-31}$

- Lack of drug knowledge ${ }^{32}$

- Psychological state ${ }^{33-37}$

- Sleep deprivation ${ }^{38-42}$

Medications ${ }^{\star^{3,11}}$ ( $\%$ of medication errors)

- Cardiovascular medications (24\%-33\%)

- Sedative or analgesic (26\%)

- Anticoagulant (11\%-20\%)

- Anti-infective (13\%)

\section{ICU environment}

- Number of medications* ${ }^{*^{7}}$ (on average, ICU patients receive 15 medications in the 24 hours before an adverse drug event)

- Frequent changes in substances and doses ${ }^{27}$

- Type of $\mathrm{ICU}^{* 7}$ (risk of preventable and potential adverse drug events is higher in medical ICUs than in surgical ICUs [unadjusted RR 1.74, 95\% CI 1.17-2.62])

- Fast pace of medical care $\mathrm{c}^{43-49}$

- Care is urgent and interventions often life-saving ${ }^{27,28}$

- Large number and complexity of interventions ${ }^{1,26,27,50}$

- Context of patient admission ${ }^{28,51-53}$

- Initiation of temporary medication therapies and lack of communication ${ }^{33}$

- Use of novel technologies and treatments ${ }^{54,55}$

- Failure to start recognized beneficial therapies ${ }^{2,56-58}$

\section{Organization}

- Patient-to-nurse ratio* ${ }^{*}$ (increasing risk of error above 1.3 to 2.0 patients per nurse in the ICU; magnitude of risk unknown)

- Frequent changes in personnel and frequent handover of care $\mathrm{e}^{59,60}$

- Difficult working conditions ${ }^{60,61}$

- Inadequate supervision ${ }^{62}$

- Premature and nighttime ICU discharge ${ }^{63}$

Note: $\mathrm{Cl}=$ confidence interval, $\mathrm{OR}=$ odds ratio, $\mathrm{RR}=$ relative risk .

* Risk factors identified in articles that satisfied our search criteria included a summary of risk estimates. 
the dose, wrong rate, wrong preparation technique, physicochemical incompatibility, wrong administration technique and wrong time.

The Critical Care Safety Study, performed by Rothschild and colleagues ${ }^{3}$ as part the Harvard Work Hours and Health Study, ${ }^{13}$ was a 1 -year prospective observational study with multifaceted determination of adverse events, including adverse drug events, in a medical ICU and a coronary care unit of a tertiary care hospital. The authors reported a similar medication error rate in both units (ICU 127.8 errors per 1000

Box 2: Strategies for preventing medication errors in the intensive care unit (ICU)

\section{Physicians}

- Awareness of risk factors*

- Medication reconciliationt (resulted in 57\% RR reduction in discharge orders being changed ${ }^{21}$

- Pharmacology education ${ }^{66-71}$

- Prescribing vigilance among physicians caring for patients with renal or liver failure*

- Good handover technique*

Nurses

- Awareness of risk factors

- Pharmacology education ${ }^{66-71}$

- Second check*

- Good handover technique*

\section{Pharmacists}

- Medication reconciliationt (resulted in 1 medication order being changed for every 2.5 patients admitted $)^{21}$

- Satellite pharmacy ${ }^{72,73}$

- Support for dose adjustments for patients with renal or liver failure*

\section{Unit directors}

- Elimination of extended physician work schedulest (resulted in a $17 \%$ reduction in serious medication errors) ${ }^{13}$

- Computerized physician order entry (effect on medication error in the ICU unclear [RR $87 \%$ to $>450 \%$ ]; no evidence of improved patient outcomes) ${ }^{14-16}$

- Clinical decision support systems ${ }^{17}$ (improved practitioner performance in 19 of 29 drug dosing or prescribing system studies $\$$ )

- Computerized intravenous devices ${ }^{18,19}$ (no effect on serious medication errors [RR 1.19] or adverse drug events [RR 1.04])

- Pharmacists' participation in rounds (reduces rate of adverse drug events due to prescription errors by $66 \%)^{20}$

- Standardized protocols (protocol-specific errors reduced to $0 \%-1 \%$ ) $^{22,23}$

- Screening programs for psychological distress ${ }^{33}$

- Bar code technology ${ }^{74-76}$

- New staff orientation (including residents) ${ }^{77-85}$

- Adequate nurse staffing ${ }^{86-89}$

- Intensivist staffing ${ }^{90}$

- Adequate working conditions and caregiver fidelity*

\section{Organization}

- Culture of safety ${ }^{91-93}$

Note: $\mathrm{RR}=$ relative risk

*No clear evidence.

†Prevention methods identified in articles that satisfied our search criteria included a summary of effect estimates.

‡Computerized decision support system effect estimate from Garg et al. ${ }^{94}$ patient-days; coronary care unit 131.5 errors per 1000 patient-days, $p=0.12$ ). Medication errors were most comwith treatment, but errors were also found in rast agents) and monitoring (e.g. glycemic monitoring and insulin therapy). The most common medication errors were orderor administering the wrong dose. Medication classes most

Our review of the literature highlighted 2 important findings. First, medication error rates vary widely among clinical settings (both ICU and non-ICU settings), patient populations and studies. The reasons for this variation are likely multifactorial, but the reasons may include different patient populations (illness severity, number and type of prescriptions) clinical practice variation, lack of uniformity of definitions, the processes under investigation (e.g., prescription, transcription), methods of reporting and the culture of the different centres reporting their data. ${ }^{2,25,64,65}$ The lack of standard definitions and reporting techniques make comparisons across organizations, regions or countries difficult. ${ }^{2}$ The single multicountry study included in our analysis did not report medication error rates across different countries. ${ }^{9}$

Second, although there are many potential risk factors for medication errors (Box 1), the strongest evidence that critically ill patients are at increased risk of a medication error are increased severity of illness; failure to document the patient's usual medication list; prescription of cardiovascular, sedative, analgesic, anticoagulant or anti-infective medications; prescription of each additional medication; admission to a medical ICU compared with a surgical ICU; and more critically ill patients per nurse (increasing risk above 1.3 to 2.0 patients per nurse in the ICU).

\section{What strategies can be used to prevent medication errors in intensive care units?}

From the 31 articles identified in our search, we identified potential strategies to prevent medication errors in the ICU (Box 2). Of these, 11 studies satisfied our inclusion criteria. These studies reported 7 prevention strategies: eliminating extended physician work schedules $(n=1)$, computerizing physician order 
entry $(n=3)$, implementing support systems for clinical decisions $(n=1)$, computerizing intravenous devices $(n=2)$, having pharmacists participate in the ICU $(n=1)$, reconciling medications $(n=1)$ and standardizing medications $(n=2)$.

\section{Physician work schedules}

A single randomized nonblinded study compared the rates of medication errors made by interns working a traditional clinical schedule with those made when extended work shifts were eliminated and the number of consecutive hours of work was limited to about $16 .{ }^{13}$ Interns in the traditional clinical schedule worked a mean 77-81 hours a week compared with 60-63 hours a week for the intervention group. Compared with interns working a traditional clinical schedule, those in the intervention group made $17.3 \%$ fewer serious medication errors (82.5 errors v. 99.7 errors per 1000 patient-days, $p=0.03$ ). Serious medication errors were similarly reduced unit-wide among all clinicians during the intervention schedule (115.5 errors v. 135.2 errors per 1000 patient-days, $p=0.03)$.

\section{Computerized physician order entry}

We found 3 studies on computerized physician order entry and medication error in the ICU. Computerized physician order entry is the main component of a clinical information system that allows physicians to enter orders directly into a computer for electronic processing, potential recommendations about dosing, and checking for duplication and drug-drug interactions. ${ }^{95}$ Computerized physician order entry targets the prescription and transcription stages of the medication process.

Shulman and colleagues ${ }^{14}$ reported the rate of medication errors before and after institution of computerized physician order entry without decision support in their 22-bed multisystem ICU. A pharmacist prospectively identified medication errors during prescription review over 26 days of data collection. Following the introduction of computerized physician order entry, the proportion of prescriptions with errors decreased from $6.7 \%$ to $4.8 \%(p<0.04)$. A second study by Colpaert and coworkers ${ }^{15}$ prospectively compared prescription errors in 2 surgical ICUs, 1 using paper-based prescriptions and 1 using computerized physician order entry. The number of prescription errors was significantly lower in the ICU that used computerized entry $(3.4 \%$ v. $27 \%, p<0.001)$. Finally, Weant and colleagues ${ }^{16}$ identified voluntarily reported medication errors before and after the implementation of computerized physician order entry in a neurosurgical ICU. Following implementation of computerized entry, there was an increase in the number of medication errors but a decrease in the number of errors resulting in patient harm. According to 2 recent systematic reviews ${ }^{96,97}$ of studies of predominantly non-ICU inpatients, the weight of evidence is that computerized physician order entry systems decrease medication errors, but they do not improve patient outcomes.

\section{Clinical decision support systems}

Clinical decision support systems can be used with computerized physician order entry; they include any knowledge-based tool integrated into clinician workflow and patient data to improve quality of care. ${ }^{98}$ We identified 1 study $^{17}$ of clinical decision support systems and medication error in the ICU, which compared the safety of anti-infective prescription before and after implementation of such a system in a 12-bed ICU. The authors reported that physicians prescribed the medication suggested by the computer for $46 \%$ of the orders and the dose and interval suggested by the computer for $93 \%$. The clinical decision support system, which was linked with computerized medical records, was able to decrease prescription of medications to which patients had reported allergies from 146 to $35(p<0.01)$, excess dose errors from 405 to 87 $(p<0.01)$ and antibiotic-susceptibility mismatches from 206 to $12(p<0.01)$. The number of reported adverse drug events following implementation decreased from 28 to $4(p<0.02)$. A systematic review of computerized decision support systems in predominantly non-ICU inpatients suggests that, although these systems may reduce error, they may not improve patient outcomes. ${ }^{94}$

\section{Computerized intravenous devices}

Computerized intravenous devices, or "smart pumps," incorporate point-of-care decision support into standard intravenous delivery systems. The bedside clinician selects a medication from a predetermined medication library and is guided through the selection of dose units (e.g., $\mu \mathrm{g} / \mathrm{kg}$ per minute or units/hour) and dose limits. Device safeguards include alerts for duplicate medication entry (medication already infusing on another channel) and dose safety limits. We identified 2 studies of computerized infusion pumps in the ICU. ${ }^{18,19}$ In the first, Rothschild and colleagues ${ }^{18}$ performed a nonblinded, prospective time series analysis that compared real-time decision support by smart pumps with no decision support in 2 cardiac surgery ICUs and 2 cardiac surgery intermediate care units. The rates of serious medication error did not differ between the intervention and control periods ( $2.41 \mathrm{v} .2 .03$ errors per 100 patient-pump-days, $p=0.124)$. In the second study, Nuckols and coworkers ${ }^{19}$ retrospectively reviewed the medical records of ICU patients in 2 hospitals before and after their conventional pumps were replaced with smart pumps. The rate of adverse intravenous drug events was similar for the 2 periods ( 4.78 v. 4.95 per 1000 patient-days, $p=0.96$ ).

\section{Pharmacist participation in the intensive care unit}

We identified 1 study $^{20}$ that reported the effects of pharmacist participation in the ICU. Adverse drug events in a medical ICU were compared before and after pharmacist participation in rounds. A coronary care unit with no pharmacist was used as a control. The rate of adverse drug events secondary to prescription errors decreased by $66 \%$, from 10.4 adverse drug events per 1000 patient-days before the intervention to 3.5 per 1000 patient-days after $(p<0.001)$. No change in adverse drug events secondary to prescription errors was observed in the control unit (10.9 v. 12.4 errors per 1000 patient-days, $p=0.76$ ). During the 9-month study period, $99 \%$ of the pharmacists' recommendations were accepted by the attending physicians. Guideline statements from both the Society of Critical Care Medicine and the American College of Clinical 
Pharmacy recommend that pharmacists regularly participate in rounds as members of the multidisciplinary critical care team to provide pharmacotherapeutic advice. ${ }^{99}$

\section{Medication reconciliation}

We identified 1 study $^{21}$ that described the use of a preICU-discharge survey to compare discharge medication orders with the patient's medical record. The aim was to identify whether discharge medications were the same as the patient's regular medications and to verify the accuracy of documented allergies. According to Pronovost and colleagues, ${ }^{21}$ the routine use of this discharge survey prevented an average of 10 medication errors per week in the 14-bed surgical ICU.

\section{Medication standardization}

We found 2 studies ${ }^{22,23}$ of medication standardization in the ICU. Wasserfallen and colleagues ${ }^{22}$ compared compliance $^{2}$ with American Society of Health-System Pharmacists' criteria $^{100}$ for prescription safety in a surgical ICU before and after implementation of a formatted order sheet. A medical ICU served as a control: physicians continued to use the usual medical order sheet but were briefed on the importance of prescribing in a correct format at the beginning of each new rotation period. The proportion of safe orders increased in both the surgical ICU $(74 \%$ v. $48 \%, p<0.001)$ and the medical ICU $(74 \%$ v. $66 \%, p<0.001)$ during the study. In the second study, McMullin and coworkers ${ }^{23}$ prospectively examined implementation of a standardized protocol for treatment of venous thromboprophylaxis to decrease errors of omission in a medical-surgical ICU. They used 5 behaviour-change strategies as part of their thromboprophylaxis safety intervention: interactive education, verbal and written prompts, computer prompts, individual performance feedback and public displays of group performance. Heparin prophylaxis increased from $60 \%$ in the baseline period, to $90 \%$ in the study period and $100 \%$ in the follow-up period $(p=0.01)$.

\section{Other prevention strategies}

We found no studies of the prevention of medication errors in critical care with various models of intensivist staffing, nurse staffing, bar code technologies, simulation, cultures of patient safety or medication reporting that satisfied our inclusion criteria. Although these strategies may be intuitive, supported by evidence in other settings or industries and even conceptually simple, further study is warranted to determine whether they prevent medication errors among critically ill patients.

\section{What can clinicians do right now to prevent medication errors?}

The quality of most studies that met our inclusion criteria was low, highlighting the fact that most interventions to prevent medication errors are not supported by high-quality evidence and that important gaps exist in the literature. Thus, a practical approach is to recognize that errors are a reality of medicine and that all health care providers have a responsibility to ensure patient safety and to use caution in promoting what are seemingly intuitive interventions. Improved medication safety may be accomplished by optimizing the safety of the medication process, eliminating situational risk factors and adopting strategies to intercept errors and mitigate their consequences. Among the 7 prevention strategies identified in articles that met our inclusion criteria, 3 can be immediately implemented by clinicians.

\section{Medication reconciliation}

As many as $50 \%$ of all medication errors occur on admission to or discharge from the ICU, and about $60 \%$ of regularly scheduled medications are stopped on ICU admission. ${ }^{21,101,102}$ Maintaining an up-to-date patientmedication list that includes long-standing medications, reasons why new medications were initiated and planned stop dates, and reasons why old medications were stopped or held may improve patient safety.

\section{Pharmacist participation}

Engaging the resources and skills of pharmacists, particularly with regard to patients with multiple risk factors or altered pharmacokinetics, is likely to improve the quality of care delivered.

\section{Medication standardization}

Many ICUs have developed protocols to facilitate the management of common important issues (e.g., prophylaxis for venous thromboembolism). Ensuring adherence to protocol for appropriate patients should improve safety.

\section{What should the approach be once an error has occurred?}

No studies about the disclosure of medication errors in critically ill patients met our inclusion criteria. However, our literature search identified articles which suggested that patients want full disclosure of harmful errors and that disclosure of medical errors is increasingly recognized as an ethical imperative ${ }^{103}$ Nonetheless, surveys show that only $17 \%-30 \%$ of physicians inform their patients when they experience a medical error. ${ }^{103-105}$ Disclosure should take place whenever a patient has suffered an iatrogenic injury and should be guided by the following principles:

- Perform in a timely fashion - as soon as possible after the injury, while ensuring the patient's well-being.

- Perform in a quiet room free of interruptions.

- Disclose facts without speculation, opinion or blame.

- Use simple, unambiguous lay words.

- Include an expression of sympathy.

- Allow time for questions.

- Document disclosure in the medical record.

\section{Resolution of the case}

Our case highlights the risks of medication error and the potentially serious consequences in critical care. First, our patient was prescribed heparin, a medication reported to be 
associated with increased risk of medication error. ${ }^{3}$ Second, medication reconciliation was not carried out when the patient's proton pump inhibitor was discontinued on admission. Third, transition of the patient's care from the ICU to the medical teaching unit provided an opportunity for the temporary administration of heparin to continue unnecessarily. Finally, either the dose of heparin or failure to monitor the patient's condition resulted in a supratherapeutic level, shown by a partial thromboplastin time of greater than 150 seconds. The medication error was disclosed to the patient's family. There was no further evidence of bleeding, and the patient was moved back to the medical teaching unit after 48 hours.

In this case, potential prevention strategies could have included the following. First, educating physicians about the risk factors for medication errors might have prevented prescription of heparin in a questionable risk-benefit scenario. Second, a structured medication reconciliation process on ICU discharge (e.g., re-prescribe all regular medications), such as the strategy proposed by Pronovost and colleagues ${ }^{21}$ might have resulted in restarting the proton-pump inhibitor. Third, a standardized process for transition of care (e.g., verbal communication, written communication, dictated transfer note) that ensures that important information on active diagnoses and important investigations and interventions are transmitted and recorded may have resulted in evaluation of the computed tomography scan result and discontinuation of heparin.

\section{Recommended reading}

- Bates DW, Spell N, Cullen DJ, et al. The costs of adverse drug events in hospitalized patients. Adverse Drug Events Prevention Study Group. JAMA 1997;277:307-11.

- Cullen DJ, Sweitzer BJ, Bates DW, et al. Preventable adverse drug events in hospitalized patients: a comparative study of intensive care and general care units. Crit Care Med 1997;25:1289-97.

- Gallagher TH, Waterman AD, Ebers AG, et al. Patients' and physicians' attitudes regarding the disclosure of medical errors. JAMA 2003;289:1001-7.

- Landrigan CP, Rothschild JM, Cronin JW, et al. Effect of reducing interns' work hours on serious medical errors in intensive care units. N Engl J Med 2004;351:1838-48.

- Leape LL, Bates DW, Cullen DJ, et al. Systems analysis of adverse drug events. ADE Prevention Study Group. JAMA 1995;274:35-43.

- Leape LL, Cullen DJ, Clapp MD, et al. Pharmacist participation on physician rounds and adverse drug events in the intensive care unit. JAMA 1999;282:267-70.

- Pronovost PJ, Angus DC, Dorman T, et al. Physician staffing patterns and clinical outcomes in critically ill patients: a systematic review. JAMA 2002;288:2151-62.

- Rothschild JM, Landrigan CP, Cronin JW, et al. The Critical Care Safety Study: the incidence and nature of adverse events and serious medical errors in intensive care. Crit Care Med 2005;33:1694-700.

- Sittig DF, Stead WW. Computer-based physician order entry: the state of the art. J Am Med Inform Assoc 1994;1:108-23.

- Volpp KG, Grande D. Residents' suggestions for reducing errors in teaching hospitals. N Engl J Med 2003;348:851-5.

\section{Conclusion}

Given the large body of literature about patient safety, ${ }^{106}$ the limited evidence available to guide clinicians in selecting strategies to prevent and disclose medication errors in critically ill patients is surprising. Nevertheless, patient safety is a first step in providing high-quality health care, and ensuring the safety of patients is everyone's responsibility and challenge.

This article has been peer reviewed.

Competing interests: None declared.

Contributors: Henry Thomas Stelfox was responsible for the conception and design of the study, the analysis and interpretation of the data, and the revision of the manuscript. Eric Camiré and Eric Moyen were responsible for design of the study, the acquisition, analysis and interpretation of data, and the drafting and revision of the manuscript. All of the authors approved the final version of the manuscript submitted for publication.

\section{REFERENCES}

1. Donchin Y, Gopher D, Olin M, et al. A look into the nature and causes of human errors in the intensive care unit. Crit Care Med 1995;23:294-300.

2. Pronovost PJ, Thompson DA, Holzmueller CG, et al. Defining and measuring patient safety. Crit Care Clin 2005;21:1-19, vii.

3. Rothschild JM, Landrigan CP, Cronin JW, et al. The Critical Care Safety Study: the incidence and nature of adverse events and serious medical errors in intensive care. Crit Care Med 2005;33:1694-700.

4. Pharmacy-nursing shared vision for safe medication use in hospitals: executive summary session. Am J Health Syst Pharm 2003;60:1046-52.

5. Hussain E, Kao E. Medication safety and transfusion errors in the ICU and beyond. Crit Care Clin 2005;21:91-110, ix.

6. Leape LL. Preventing adverse drug events. Am J Health Syst Pharm 1995;52:379-82.

7. Cullen DJ, Sweitzer BJ, Bates DW, et al. Preventable adverse drug events in hospitalized patients: a comparative study of intensive care and general care units. Crit Care Med 1997;25:1289-97.

8. Pronovost PJ, Weast B, Holzmueller CG, et al. Evaluation of the culture of safety: survey of clinicians and managers in an academic medical center. Qual Saf Health Care 2003;12:405-10.

9. Valentin A, Capuzzo M, Guidet B, et al. Patient safety in intensive care: results from the multinational Sentinel Events Evaluation (SEE) study. Intensive Care Med 2006;32:1591-8

10. Sinopoli DJ, Needham DM, Thompson DA, et al. Intensive care unit safety incidents for medical versus surgical patients: a prospective multicenter study. J Crit Care 2007;22:177-83.

11. Calabrese AD, Erstad BL, Brandl K, et al. Medication administration errors in adult patients in the ICU. Intensive Care Med 2001;27:1592-8.

12. Tissot E, Cornette C, Demoly P, et al. Medication errors at the administration stage in an intensive care unit. Intensive Care Med 1999;25:353-9.

13. Landrigan CP, Rothschild JM, Cronin JW, et al. Effect of reducing interns' work hours on serious medical errors in intensive care units. $N$ Engl J Med 2004:351:1838-48.

14. Shulman R, Singer M, Goldstone J, et al. Medication errors: a prospective cohort study of hand-written and computerised physician order entry in the intensive care unit. Crit Care 2005;R5:16-21.

15. Colpaert K, Claus B, Somers A, et al. Impact of computerized physician order entry on medication prescription errors in the intensive care unit: a controlled crosssectional trial. Crit Care 2006;10:R21.

16. Weant KA, Cook AM, Armitstead JA. Medication-error reporting and pharmacy resident experience during implementation of computerized prescriber order entry. Am J Health Syst Pharm 2007;64:526-30.

17. Evans RS, Pestotnik SL, Classen DC, et al. A computer-assisted management program for antibiotics and other antiinfective agents. N Engl J Med 1998;338:232-8.

18. Rothschild JM, Keohane CA, Cook EF, et al. A controlled trial of smart infusion pumps to improve medication safety in critically ill patients. Crit Care Med 2005;33:533-40.

19. Nuckols TK, Bower AG, Paddock SM, et al. Programmable infusion pumps in ICUs: an analysis of corresponding adverse drug events. J Gen Intern Med 2008;23(Suppl 1):41-5

20. Leape LL, Cullen DJ, Clapp MD, et al. Pharmacist participation on physician rounds and adverse drug events in the intensive care unit. JAMA 1999;282:267-70.

21. Pronovost P, Weast B, Schwarz M, et al. Medication reconciliation: a practical tool to reduce the risk of medication errors. J Crit Care 2003;18:201-5.

22. Wasserfallen JB, Butschi AJ, Muff P, et al. Format of medical order sheet improves security of antibiotics prescription: the experience of an intensive care unit. Crit Care Med 2004;32:655-9. 
23. McMullin J, Cook D, Griffith L, et al. Minimizing errors of omission: behavioural reenforcement of heparin to avert venous emboli: the BEHAVE study. Crit Care Med 2006;34:694-9.

24. Beckmann U, Bohringer C, Carless R, et al. Evaluation of two methods for quality improvement in intensive care: facilitated incident monitoring and retrospective medical chart review. Crit Care Med 2003;31:1006-11.

25. Andrews LB, Stocking C, Krizek T, et al. An alternative strategy for studying adverse events in medical care. Lancet 1997;349:309-13.

26. Giraud T, Dhainaut JF, Vaxelaire JF, et al. Iatrogenic complications in adult intensive care units: a prospective two-center study. Crit Care Med 1993;21:40-51.

27. Weingart SN, Wilson RM, Gibberd RW, et al. Epidemiology of medical error. BMJ 2000;320:774-7

28. Brennan TA, Leape LL, Laird NM, et al. Incidence of adverse events and negligence in hospitalized patients. Results of the Harvard Medical Practice Study I. $N$ Engl J Med 1991;324:370-6.

29. Morrison AL, Beckmann U, Durie M, et al. The effects of nursing staff inexperience (NSI) on the occurrence of adverse patient experiences in ICUs. Aust Crit Care 2001;14:116-21.

30. Lesar TS, Briceland LL, Delcoure K, et al. Medication prescribing errors in a teaching hospital. JAMA 1990;263:2329-34.

31. Wu AW, Folkman S, McPhee SJ, et al. Do house officers learn from their mistakes? JAMA 1991;265:2089-94.

32. Leape LL, Bates DW, Cullen DJ, et al. Systems analysis of adverse drug events. ADE Prevention Study Group. JAMA 1995;274:35-43.

33. Fahrenkopf AM, Sectish TC, Barger LK, et al. Rates of medication errors among depressed and burnt out residents: prospective cohort study. BMJ 2008;336:488-91.

34. Gopal R, Glasheen JJ, Miyoshi TJ, et al. Burnout and internal medicine resident work-hour restrictions. Arch Intern Med 2005;165:2595-600

35. Goitein L, Shanafelt TD, Wipf JE, et al. The effects of work-hour limitations on resident well-being, patient care, and education in an internal medicine residency program. Arch Intern Med 2005;165:2601-6.

36. Shanafelt TD, Bradley KA, Wipf JE, et al. Burnout and self-reported patient care in an internal medicine residency program. Ann Intern Med 2002;136:358-67.

37. West CP, Huschka MM, Novotny PJ, et al. Association of perceived medical errors with resident distress and empathy: a prospective longitudinal study. JAMA 2006;296:1071-8.

38. Gaba DM, Howard SK. Patient safety: fatigue among clinicians and the safety of patients. N Engl J Med 2002;347:1249-55.

39. Grantcharov TP, Bardram L, Funch-Jensen P, et al. Laparoscopic performance after one night on call in a surgical department: prospective study. $B M J$ 2001;323:1222-3

40. Veasey S, Rosen R, Barzansky B, et al. Sleep loss and fatigue in residency training: a reappraisal. JAMA 2002;288:1116-24

41. Weinger MB, Ancoli-Israel S. Sleep deprivation and clinical performance. JAMA 2002;287:955-7.

42. Ayas NT, Barger LK, Cade BE, et al. Extended work duration and the risk of selfreported percutaneous injuries in interns. JAMA 2006;296:1055-62.

43. Kane-Gill S, Weber RJ. Principles and practices of medication safety in the ICU. Crit Care Clin 2006;22:273-90.

44. Coomber S, Todd C, Park G, et al. Stress in UK intensive care unit doctors. $\mathrm{Br} \mathrm{J}$ Anaesth 2002;89:873-81.

45. Pronovost PJ, Jenckes MW, Dorman T, et al. Organizational characteristics of intensive care units related to outcomes of abdominal aortic surgery. JAMA 1999;281:1310-7.

46. Chisholm CD, Collison EK, Nelson DR, et al. Emergency department workplace interruptions: are emergency physicians "interrupt-driven" and "multitasking"? Acad Emerg Med 2000; 7:1239-43.

47. Collins S, Currie L, Bakken S, et al. Interruptions during the use of a CPOE system for MICU rounds. AMIA Annu Symp Proc 2006:895.

48. Flynn EA, Barker KN, Gibson JT, et al. Impact of interruptions and distractions on dispensing errors in an ambulatory care pharmacy. Am J Health Syst Pharm 1999, 56:1319-25.

49. Volpp KG, Grande D. Residents' suggestions for reducing errors in teaching hospitals. N Engl J Med 2003;348:851-5.

50. Wright D, Mackenzie SJ, Buchan I, et al. Critical incidents in the intensive therapy unit. Lancet 1991;338:676-8.

51. Duke GJ, Green JV. Outcome of critically ill patients undergoing interhospital transfer. Med J Aust 2001;174:122-5.

52. Beckmann U, Gillies DM, Berenholtz SM, et al. Incidents relating to the intra-hospital transfer of critically ill patients. An analysis of the reports submitted to the Australian Incident Monitoring Study in Intensive Care. Intensive Care Med 2004;30:1579-85.

53. Wolff AM, Bourke J, Campbell IA, et al. Detecting and reducing hospital adverse events: outcomes of the Wimmera clinical risk management program. Med J Aust 2001;174:621-5.

54. Brown SL, Bogner MS, Parmentier CM, et al. Human error and patient-controlled analgesia pumps. J Intraven Nurs 1997;20:311-6.

55. Lin L, Isla R, Doniz K, et al. Applying human factors to the design of medical equipment: patient-controlled analgesia. J Clin Monit Comput 1998;14:253-63.

56. McGlynn EA, Asch SM, Adams J, et al. The quality of health care delivered to adults in the United States. N Engl J Med 2003;348:2635-45.

57. Rogers WJ, Bowlby LJ, Chandra NC, et al. Treatment of myocardial infarction in the United States (1990 to 1993). Observations from the National Registry of Myocardial Infarction. Circulation 1994;90:2103-14.
58. Ellerbeck EF, Jencks SF, Radford MJ, et al. Quality of care for Medicare patients with acute myocardial infarction. A four-state pilot study from the Cooperative Cardiovascular Project. JAMA 1995;273:1509-14.

59. Catchpole KR, de Leval MR, McEwan A, et al. Patient handover from surgery to intensive care: using Formula 1 pit-stop and aviation models to improve safety and quality. Paediatr Anaesth 2007;17:470-8.

60. Roseman C, Booker JM. Workload and environmental factors in hospital medication errors. Nurs Res 1995;44:226-30.

61. Donchin Y, Seagull FJ. The hostile environment of the intensive care unit. Curr Opin Crit Care 2002;8:316-20.

62. Oddone EZ, Waugh RA, Samsa G, et al. Teaching cardiovascular examination skills: results from a randomized controlled trial. Am J Med 1993;95:389-96.

63. Goldfrad C, Rowan K. Consequences of discharges from intensive care at night. Lancet 2000;355:1138-42.

64. O'Neil AC, Petersen LA, Cook EF, et al. Physician reporting compared with medical-record review to identify adverse medical events. Ann Intern Med 1993;119: 370-6.

65. Michel P, Quenon JL, de Sarasqueta AM, et al. Comparison of three methods for estimating rates of adverse events and rates of preventable adverse events in acute care hospitals. BMJ 2004;328:199.

66. Bion JF, Heffner JE. Challenges in the care of the acutely ill. Lancet 2004; 363:970-7.

67. Kizer KW. Patient safety: a call to action: a consensus statement from the National Quality Forum. MedGenMed 2001;3:10.

68. Battles JB, Shea CE. A system of analyzing medical errors to improve GME curricula and programs. Acad Med 2001;76:125-33.

69. Weingart SN. House officer education and organizational obstacles to quality improvement. Jt Comm J Qual Improv 1996;22:640-6.

70. Barach P, Berwick DM. Patient safety and the reliability of health care systems. Ann Intern Med 2003;138:997-8.

71. Davis D, O'Brien MA, Freemantle N, et al. Impact of formal continuing medical education: do conferences, workshops, rounds, and other traditional continuing education activities change physician behavior or health care outcomes? JAMA 1999;282:867-74.

72. Wadd WB, Blissenbach TJ. Medication-related nursing time in centralized and decentralized drug distribution. Am J Hosp Pharm 1984;41:477-80.

73. Parshuram CS, To T, Seto W, et al. Systematic evaluation of errors occurring during the preparation of intravenous medication. CMAJ 2008;178:42-8.

74. Mills PD, Neily J, Mims E, et al. Improving the bar-coded medication administration system at the Department of Veterans Affairs. Am J Health Syst Pharm 2006;63:1442-7.

75. Patterson ES, Cook RI, Render ML. Improving patient safety by identifying side effects from introducing bar coding in medication administration. J Am Med Inform Assoc 2002;9:540-53.

76. Poon EG, Cina JL, Churchill W, et al. Medication dispensing errors and potential adverse drug events before and after implementing bar code technology in the pharmacy. Ann Intern Med 2006;145:426-34.

77. Paice E, Aitken M, Cowan G, et al. Trainee satisfaction before and after the Calman reforms of specialist training: questionnaire survey. BMJ 2000;320:832-6.

78. Heffner JE, Ellis R, Zeno B. Safety in training and learning in the intensive care unit. Crit Care Clin 2005;21:129-48, ix.

79. Seoane L, Taylor DE. Medical errors in the intensive care unit: can we find the black box before the patient crashes? Crit Care Med 2003;31:2553-4.

80. Wolf FM, Gruppen LD, Billi JE. Use of the competing-hypotheses heuristic to reduce 'pseudodiagnosticity.' J Med Educ 1988;63:548-54.

81. Wheeler DW, Carter JJ, Murray LJ, et al. The effect of drug concentration expression on epinephrine dosing errors: a randomized trial. Ann Intern Med 2008;148:11-4.

82. Schwid HA, Rooke GA, Carline J, et al. Evaluation of anesthesia residents using mannequin-based simulation: a multi-institutional study. Anesthesiology 2002;97: 1434-44.

83. Garnerin P, Perneger T, Chopard P, et al. Drug selection errors in relation to medication labels: a simulation study. Anaesthesia 2007;62:1090-4.

84. Croley WC, Rothenberg DM. Education of trainees in the intensive care unit. Crit Care Med 2007;35(2 Suppl):S117-21.

85. Fox-Robichaud AE, Nimmo GR. Education and simulation techniques for improving reliability of care. Curr Opin Crit Care 2007;13:737-41.

86. Kane RL, Shamliyan TA, Mueller C, et al. The association of registered nurse staffing levels and patient outcomes: systematic review and meta-analysis. Med Care 2007; 45:1195-204.

87. Beckmann U, Baldwin I, Durie M, et al. Problems associated with nursing staff shortage: an analysis of the first 3600 incident reports submitted to the Australian Incident Monitoring Study (AIMS-ICU). Anaesth Intensive Care 1998;26:396-400.

88. Aiken LH, Clarke SP, Sloane DM, et al. Hospital nurse staffing and patient mortality, nurse burnout, and job dissatisfaction. JAMA 2002;288:1987-93.

89. Needleman J, Buerhaus P, Mattke S, et al. Nurse-staffing levels and the quality of care in hospitals. N Engl J Med 2002;346:1715-22.

90. Pronovost PJ, Angus DC, Dorman T, et al. Physician staffing patterns and clinical outcomes in critically ill patients: a systematic review. JAMA 2002;288:2151-62.

91. Dodek P, Keenan S, Cook D, et al. Evidence-based clinical practice guideline for the prevention of ventilator-associated pneumonia. Ann Intern Med 2004;141: 305-13.

92. Chastre J, Fagon JY. Ventilator-associated pneumonia. Am J Respir Crit Care Med 2002;165:867-903. 
93. Berenholtz SM, Pronovost PJ, Lipsett PA, et al. Eliminating catheter-related bloodstream infections in the intensive care unit. Crit Care Med 2004;32:2014-20.

94. Garg AX, Adhikari NK, McDonald H, et al. Effects of computerized clinical decision support systems on practitioner performance and patient outcomes: a systematic review. JAMA 2005;293:1223-38.

95. Sittig DF, Stead WW. Computer-based physician order entry: the state of the art. $J$ Am Med Inform Assoc 1994;1:108-23.

96. Eslami S, Keizer NF, Abu-Hanna A. The impact of computerized physician medication order entry in hospitalized patients - a systematic review. Int J Med Inform 2008;77:365-76

97. Shamliyan TA, Duval S, Du J, et al. Just what the doctor ordered. Review of the evidence of the impact of computerized physician order entry system on medication errors. Health Serv Res 2008;43:32-53.

98. Kuperman GJ, Bobb A, Payne TH, et al. Medication-related clinical decision support in computerized provider order entry systems: a review. J Am Med Inform As soc 2007; 14:29-40.

99. Rudis MI, Brandl KM. Position paper on critical care pharmacy services. Society of Critical Care Medicine and American College of Clinical Pharmacy Task Force on Critical Care Pharmacy Services. Crit Care Med 2000;28:3746-50.

100. ASHP guidelines on preventing medication error in hospitals. Am J Hosp Pharm 1993;50:305-14.
101. Campbell AJ, Bloomfield R, Noble DW. An observational study of changes to long-term medication after admission to an intensive care unit. Anaesthesia 2006;61:1087-92

102. Bates DW, Spell N, Cullen DJ, et al. The costs of adverse drug events in hospitalized patients. Adverse Drug Events Prevention Study Group. JAMA 1997;277:307-11.

103. Gallagher TH, Waterman AD, Ebers AG, et al. Patients' and physicians' attitudes regarding the disclosure of medical errors. JAMA 2003;289:1001-7.

104. Blendon RJ, DesRoches CM, Brodie M, et al. Views of practicing physicians and the public on medical errors. N Engl J Med 2002;347:1933-40.

105. Lehmann LS, Puopolo AL, Shaykevich S, et al. Iatrogenic events resulting in intensive care admission: frequency, cause, and disclosure to patients and institutions. Am J Med 2005;118:409-13.

106. Stelfox HT, Palmisani S, Scurlock C, et al. The "To Err is Human" report and the patient safety literature. Qual Saf Health Care 2006;15:174-8.

Correspondence to: Dr. Henry Thomas Stelfox, Department of Critical Care Medicine, Foothills Medical Centre, Rm. EG23A, 1403-29 St. NW, Calgary AB T2N 2T9; fax 403 283-9994; tom.stelfox@albertahealthservices.ca 